\title{
Chapter 9 \\ Housing Policies for Rural Migrant Workers in China
}

\author{
Yeqiang Wang and Xin Dong
}

\begin{abstract}
Lack of housing security is a major problem for rural migrant workers in China. This chapter explores the range and depth of housing problems facing rural migrants. These challenges include issues of affordability and poor housing quality and administrative barriers that inhibit access to commercial housing and housing welfare programmes. There is a big difference between the housing consumption pattern of migrant workers in the city and that in the countryside. This is due to large discrepancies in levels of access to good quality accommodation between migrants from rural areas and the established urban population. These inequalities are exacerbated by inherited forms of residential registration that adversely affect rural migrants settling in towns and cities. The situation is further exacerbated by land use regulations that restrict the construction of collective dormitories for rural migrant workers. The key is to promote the system reform of rural land and speed up the establishment of a free market homestead and rural housing. Policy responses over the past twenty years are evaluated, and recommendations for future policy development are proposed to improve housing conditions, including reform of land use regulations and improved property rights for migrants.
\end{abstract}

Keyword Migrant workers • Housing Policies • Urban housing security system • Dual housing consumption modes $\cdot$ Household registration system

\subsection{Introduction}

The current lack of urban housing security for rural migrants in China constitutes an important barrier to their "citizenisation' ${ }^{1}$ - the acquisition of full rights as citizens_-and hinders the process of urbanisation in China. The lack of proper housing

\footnotetext{
${ }^{1}$ Citizenisation refers to rural migrants who have worked in the city for a long time. They need to be given the same rights as urban residents in education, medical care, social security and other aspects, so as to integrate into the city in culture, psychology, lifestyle and other aspects.
}

\footnotetext{
Y. Wang $(\varangle) \cdot$ X. Dong

27 Wangfujing Street, Dongcheng District, Beijing, China

e-mail: wangyeqiang517@163.com
} 
or poor housing conditions hinders rural migrant workers from developing a sense of belonging in the city. Housing is one of the most basic physical and social requirements and a lack of housing security makes it harder for rural migrants to integrate into urban life. The increased sense of alienation and psychological distance from urban society is a potentially important source of urban disharmony.

In this chapter, we describe the challenges facing housing provision for rural migrants in China and evaluate the policies that have been introduced. In Sect. 2, we summarise the main housing problems facing rural migrants (Sect. 2), and in Sect. 3, we provide an overview of the changes in China's housing policies. In Sect. 4, we evaluate these housing policies and consider the implications for future policy development in Sect. 5. We conclude with a brief summary.

\subsection{Housing for Rural Migrants}

This section considers the housing situation for rural migrants from three directions: housing conditions, housing security, housing affordability, and government and market failures.

\subsubsection{Housing Conditions}

Lack of adequate living space, poor environmental quality, and inadequate living facilities all shape the general housing experience for rural migrants in China. Compared with the increasing per capita living area and improving living conditions of permanent urban residents, urban housing for rural migrants falls far short of what is becoming the national norm. Because of their poorer economic status and lack of official local household registration, rural migrants can only choose rented accommodation. The explosive growth in urban populations and rising real estate prices in recent years have forced them to settle mainly in older urban neighbourhoods that are relatively remote, inaccessible, seriously polluted, and lacking in green or open space, or else in rural areas on the edge of the city. This has serious implications both for their health and their personal security. 


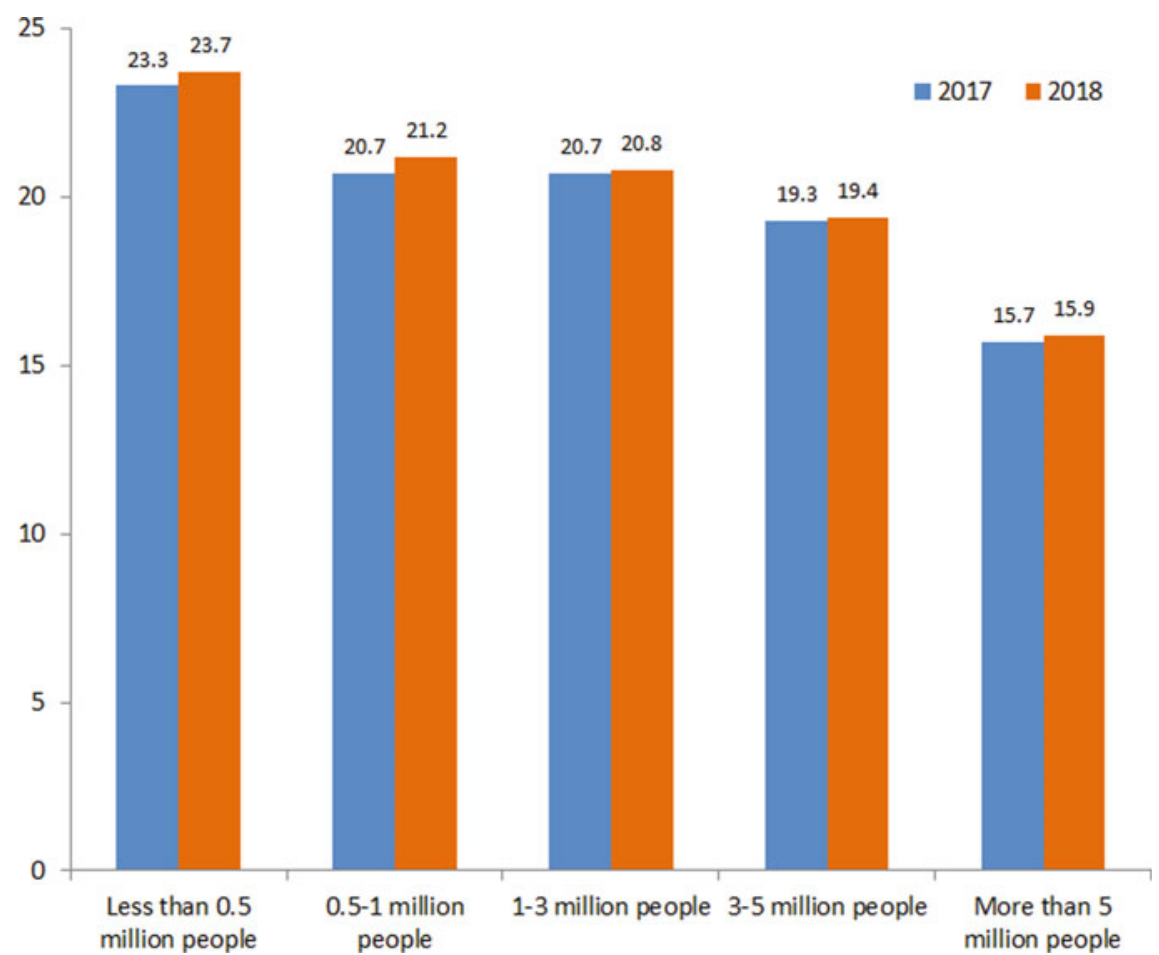

Fig. 9.1 Per capita living area of rural migrants in cities by city size

Nevertheless, in recent years, across a range of areas, including housing location, resources and facilities, as well as lifestyle, the living conditions of rural migrants ${ }^{2}$ in cities have generally improved.

The Monitoring and Survey Report on Rural Migrant Workers of the National Bureau of Statistics of China have reported on the housing locations, and access to resources and facilities for rural migrants since 2016. The per capita living area of urban-rural migrants was 20.2 square metres in 2018 , an increase of 0.4 square metres over the previous year. The proportion of rural migrants with a per capita living area of just five square metres or less accounted for $4.4 \%$ of the total, a decrease of $0.2 \%$ over the previous year. Figure 9.1 shows how the per capita living area decreases with

\footnotetext{
${ }^{2}$ The term rural migrant workers refers to workers who still hold rural registered permanent residence and are engaged in non-agricultural industries in cities or have been employed outside their hometown for six months or above. The term local rural migrant workers refers to those who work within the township area of their household registration, whereas outgoing rural migrant workers refers to those who work outside the township area of their household registration. The term urban migrant workers refers to those who live in urban areas. The urban area is divided according to the Provisions on Statistical Division of Urban and Rural Areas of the National Bureau of Statistics, and is consistent with the territorial scope for calculating the population urbanisation rate.
} 
city size and also shows how the living area of rural migrants increased modestly across all cities between 2017 and 2018.

\subsubsection{Housing Security}

The proportion of rural migrants provided with housing by government-funded work units danwe $i^{3}$ or employers has declined significantly. While the proportion of rural migrants purchasing housing has increased, the proportion of rural migrants enjoying housing security is still very low. Rental accommodation has become the primary form of accommodation for rural migrants in Chinese cities.

Rental housing has overtaken the work unit dormitory as the most prominent form of accommodation for rural migrants, but a considerable proportion still live in construction site sheds and on production and operation sites. The proportion of rural migrants who commute to work from home has increased significantly, while the proportion of rural migrants purchasing housing in the cities where they work has increased slightly though it is still very low. In $2015,37 \%$ of outgoing rural migrants rented houses, $28.7 \%$ lived in dormitories, $15.9 \%$ lived in construction site sheds or on production and operation sites, $14 \%$ commuted from home, $1.3 \%$ purchased housing in cities where they worked, and 'others' accounted for $3.1 \%$ of the total.

In 2016, the statistical calibration for the Monitoring and Survey Report on Rural Migrant Workers of the National Bureau of Statistics changed from source to destination of rural migrant workers. In 2016, $62.4 \%$ of rural migrant workers lived in rented houses, of which $61 \%$ lived in rented private houses, and $13.4 \%$ lived in houses provided by work units or employers. In 2018, $61.3 \%$ of urban-rural migrant workers lived in rented houses, an increase of $0.3 \%$ over the previous year; $12.9 \%$ lived in houses provided by work units or employers, $0.4 \%$ lower than that of the previous year; and $19 \%$ purchased housing, the same as the previous year. Some $17.4 \%$ purchased commercial housing, the same as the previous year.

Various factors contribute to the pressures facing rural migrants during the transition to urban life: the restriction of household registration, difficulties for their children entering school, a higher cost of living and limited living space. Most rural migrant workers usually live and work in the city alone, and often rent housing jointly with colleagues and workers to save rent. This results in a relatively lonely lifestyle, forced to live apart from their families. The dislocation and separation of partners,

\footnotetext{
${ }^{3}$ danwei refers to the employing organisation other than the enterprise. During the pre-reform period, most urban employers were either state owned institutions, state owned enterprises, or collectively owned enterprises. They were all referred as 'danwei' (work unit). Every working age person in a city had a 'danwei'. Since the reforms, the urban economy has become mixed, with more privately owned companies, institutions and enterprises, but the phrase danwei (work unit) is still in use. In general, it now means 'employer', including private sector employers as well as those in state-run enterprises. Danwei and work unit, both are used commonly in Chinese studies. This is the sense in which they are used in this chapter-work units but not necessarily government funded ones.
} 
parents and children, siblings and other relatives is a common feature of migrant life in urban China. It is not conducive to the healthy development of family life and leads to complex social problems around issues such as left-behind children-offspring of migrant workers left in the care of rural relatives while their parents work and live in the city.

The proportion of rural migrants purchasing housing near their places of work has increased and is a prominent trend. According to data from the National Bureau of Statistics' Monitoring and Survey Report on Rural Migrant Workers in 2015, $1.3 \%$ of rural migrants purchased housing in places where they work. In 2016, $17.8 \%$ of urban-rural migrants purchased housing, an increase of $0.5 \%$ over the previous year. Some $16.5 \%$ of these rural migrants purchased commercial houses, an increase of $0.8 \%$ over the previous year. Based on data collected in 2016, in $2015,17.2 \%$ of urban-rural migrants purchased housing, while in 2015 , only $1.3 \%$ of purchased housing close to their work-place. Such a large gap is probably due to migrants purchasing properties in small and medium-sized communities nearer their hometown.

At the same time, the proportion of rural migrant workers enjoying urban housing security is still very low. In 2016, less than $3 \%$ of urban-rural migrant workers purchased affordable housing and took public rental housing lets. In 2018, 2.9\% of these workers enjoyed affordable housing, an increase of $0.2 \%$ over the previous year. Among them, $1.3 \%$ rented accommodation from publicly owned sources, an increase of $0.2 \%$ over the previous year; and $1.6 \%$ purchased affordable housing, the same as the previous year. It can be seen that the role of urban housing security in solving the housing problem of rural migrants is still very limited.

\subsubsection{Housing Affordability}

The ability to afford accommodation can be further refined to reflect rental or purchase payments. The rent-income ratio of rural migrant workers does not exceed the reasonable standard, but the corresponding housing conditions are poor. In 2015, the per capita monthly living expenses of rural migrant workers in cities and towns amounted to $¥ 475$, the per capita monthly income was $¥ 3,072$, and the proportion of living expenses to income was $15.5 \%$. Internationally, the accepted reasonable level for the rent-income ratio is no more than $30 \%$. According to this standard, it appears that Chinese rural migrants do not lack sufficient levels of affordable housing in cities and towns. However, their low living expenses correspond to relatively poor housing conditions. A considerable number of rural migrants live in urban villages (Chap. 6), shanty towns (Chap. 7) and work sheds.

In the case of the affordability of purchased housing, the house price-to-income ratio shows that the ability of rural migrants to purchase housing is generally insufficient. The specific calculation method for the house price-to-income ratio is as follows: the ratio of the average sales price of commercial housing to the average annual household income of outgoing rural migrants. The average sales 
Table 9.1 House price-to-income ratio of outgoing rural migrants' families in various regions

\begin{tabular}{l|c|c|c|c|c}
\hline & 2008 & 2009 & 2010 & 2011 & 2012 \\
\hline Whole country & 9.9 & 11.9 & 10.6 & 9.5 & 9.3 \\
\hline Eastern region & 13.1 & 15.8 & 13.9 & 12.1 & 11.8 \\
\hline Central region & 6.6 & 7.5 & 7.3 & 7.1 & 6.8 \\
\hline Western region & 7.5 & 8.5 & 8.1 & 7.7 & 7.5 \\
\hline
\end{tabular}

Data source Calculated according to the data of 2012 National Monitoring and Survey Report on Rural Migrant Workers of the National Bureau of Statistics and China Statistical Yearbook

price for commercial housing (yuan/flat) is calculated by multiplying the average sales price of commercial housing $\left(\mathrm{yuan} / \mathrm{m}^{2}\right.$ ) by the per capita housing construction area $\left(\mathrm{m}^{2}\right)$ and then multiplying the average household population of urban residents (person/household) (assuming that each household has a flat). The average annual household income of rural migrants (yuan/household) is calculated by multiplying the assumed average number of personnel working away from their homes per household ${ }^{4}$ (person/household) by their average annual income (yuan/person). By comparing the two, we can obtain the house price-to-income ratio for migrants' families in various regions from 2008 to $2012,{ }^{5}$ as shown in Table 9.1.

From Table 9.1, it can be seen that from 2008 to 2012, the house price-to-income ratio for rural migrants' families in the national housing market was 9.3-11.9, 11.815.8 in the eastern region, 6.6-7.5 in the central region, and 7.5-8.1 in the western region housing market. The lower the house price-to-income ratio, the higher the level of affordability. The comparable international range for a reasonable houseprice-to-income ratio is 4-6. However, considering the actual situation in China, it is more suitable to adopt the house price-to-income ratio range of 5-7 as a reasonable standard (Dong 2012). According to this measure, in recent years, the overall house price-to-income ratio for rural migrants' families in the national housing market has exceeded the reasonable standard, indicating a generally insufficient level of housing affordability for such families in China. The house price-to-income ratio for such families in the eastern region is much higher than the reasonable range, indicating a low level of affordable housing in the eastern region. In central and western regions, the house price-to-income ratio for these families is slightly higher than the reasonable standard. In some years, the house price-to-income ratio for the families of rural migrants in the central region lies within the reasonable range, indicating a good level of affordable accommodation. On occasion, there is a better level of housing affordability in the central region than in the western region.

\footnotetext{
${ }^{4}$ Outgoing migrant workers: refers to rural labourers who have worked outside their township area for six months or more during the survey year.

${ }^{5}$ Due to the limitation of data acquisition, only the relevant data from 2008 to 2012 can be acquired.
} 


\subsubsection{Government and Market Failures}

With the rapid growth in the number of rural migrants, the increasing time they spend living in cities, and greater measures to improve integration, the housing problems of rural migrants are receiving more attention. The Several Opinions of the State Council on Solving the Problems of Rural Migrant Workers promulgated in 2006 proposed to solve housing problems through multiple channels to ensure that accommodation meets basic health and safety conditions. The Several Opinions of the State Council on Solving Housing Difficulties of Urban Low-income Households promulgated in 2007 included rural migrants alongside other urban groups with housing difficulties. In 2007, the Ministry of Construction, the Development and Reform Commission and other departments jointly issued the document, Guiding Opinions on Improving the Living Conditions of Rural Migrant Workers, proposing that employers should take responsibility for improving living conditions for workers. These documents established the basic direction of housing policies for rural migrants. Some areas have also actively resolved migrants' housing problems, introducing measures which include the establishment of apartments for rural migrants (affordable rental housing), the inclusion of qualified rural migrants into the urban housing security system, the establishment of a housing provident fund system for rural migrants, and financial and tax support for rural migrants to purchase housing. The general situation, however, is one of both market and government failure, mostly manifested in the following four aspects:

(i) Urban-rural division of the household registration system: this is the primary root cause of the housing problems facing rural migrants. China still implements the dual household registration structure that has perpetuated urbanrural divisions since the 1950s. This creates a significant obstacle for rural migrants entering the city. The cultural level and social status of rural migrants makes it difficult for them to live and work in the city, and China's household registration system reinforces the disparity at a fundamental level. Rural migrants have never been able to enjoy the same medical, employment, pension, education and other rights as urban residents. Restrictions on the status and 'identity' of rural migrants increase their living costs and make it difficult for them to integrate and generate a sense of belonging. The dual household registration system and the inequalities it creates is the fundamental cause behind the housing problems facing rural migrants.

(ii) Commercial Housing Market Barriers to Entry: The income level of the vast majority of rural migrants is far lower than the urban house price and rent level. Except when an employer provides housing, most migrants have to rent from private landlords. However, due to their limited economic capacity, migrants can only rent private houses from farmers on the urban-rural fringe or relatively low-priced substandard housing in the city centre. The demand for housing for rural migrants is very strong, but the market will not automatically produce a supply to match this demand. The market fails to resolve the housing problems of rural migrants. Urban villages comprising rural migrants and 
collective rental patterns reflect the disparity between supply and demand. If the supply structure is not adjusted, these urban villages and collective rental patterns will be difficult to resolve and will have an adverse impact on the entire urban housing market. See Chap. 6 for further discussion of urban villages.

(iii) Exclusion from the Urban Housing Security System: Under the urban-rural dual household registration system, rural migrants are regarded as an 'external population' and 'temporary resident population.' They have not been subject to status change and cannot enjoy the same protection rights as urban residents. Although the Guiding Opinions on Accelerating the Development of Public Rental Housing jointly issued by seven ministries and commissions in 2010 proposed that rural migrants shall be included in the urban housing security system, so far, the coverage of housing security system for rural migrants is still insufficient, and rural migrants are still excluded from the urban housing security system in China. Although some cities have proposed to include rural migrants in the urban housing security system, there are too many restrictions, the threshold for rural migrants to enter the urban housing security system is too high, and government failures do exist.

(iv) Land Use Policy: At present, there are three ways to construct such collective dormitories: (1) enterprises in the development zones or industrial parks use transferred land to build staff dormitories near the factory production areas; (2) enterprises and agricultural collectives cooperate to build dormitories using collective farm land in the urban-rural fringe area; (3) renovate or construct dormitories for rural migrants using redundant factories left by bankrupt or closed enterprises. The problem is that these solutions conflict with current land policy. For instance, the use of transferred industrial land to build dormitories for rural migrants conflicts with the current industrial land policy; the use of collective land to build dormitories for rural migrants conflicts with the current collective construction land transfer policy; the use of redundant factories as dormitories conflicts with the current land acquisition and reserve policy.

In addition, there needs to be further improvement in the exploration and development of local policy. For example, sources of funds that could provide affordable housing are uncertain, there is a lack of suitable housing stock, a lack of detailed rules for the housing provident fund system, and housing financial services for rural migrants are almost non-existent'. Therefore, much still needs to be done to improve the housing security system, to boost housing supply and to match the needs and characteristics of rural migrants. 


\subsection{Changes to Housing Policies for Rural Migrant Workers}

The State Council's government work report in 2016 reaffirmed the 'three 100 million people' policy goal, ${ }^{6}$ and proposed 'to achieve the settlement of about 100 million agricultural transfer populations and other permanent residents in cities and towns'. It declares that urbanisation is 'the biggest potential of domestic demand and development momentum in China', and established a policy objective 'to achieve the urbanisation rate of permanent residents of $60 \%$ and the urbanisation rate of household registration of $45 \%$ by 2020.' These goals are related to the migration of agricultural transfer population, which is closely related to urbanisation and economic promotion. The report of the 19th National Congress in 2017 proposed to 'take urban agglomeration as the main body to build a coordinated development pattern of large and medium-sized cities and small towns, and accelerate the citizenisation of agricultural transfer population.'

Migration involves two related processes. The first is the migration of populations from their place of origin, and the second is the settlement of these migrants in their place of destination (Berger and Blomquist 1992; Cai 2001). Rural-urban migration has become an important issue in developing countries (Brueckner and Lall 2015). Migration processes can also be further sub-divided into permanent migration and non-permanent migration. As the term suggests, permanent migration refers to patterns whereby migrants intend to live at their chosen destination for a long time without returning to their original places of residence. Conversely, non-permanent migration refers to migration patterns where migrants do not, or do not intend to, stay for an extended period (Ma and Meng 2003; Cai and Wang 2007). At present, the key issue for Chinese urbanisation is the second process of population migration, that is, realising and consolidating permanent migrations and the 'citizenisation' of agricultural migrants within urban centres. This is an important aspect of what has become known as 'New Urbanisation' (Dong 2015).

Housing has become an increasingly important factor affecting population migration. Even without institutional barriers such as household registration, current problems within China's housing market erects a practical barrier to family migration. Housing issues have become the dominant factor in the social exclusion of migrants in major cities (Zhao 1999a, b; Li 2008). Where migrants are unable to bear the costs of urban housing, it becomes impossible for them to settle permanently or for lengthy periods. This creates transient or circular migration patterns, which prolongs the process of rural-urban migration and slows down urbanisation (Ren and An 2011). Meanwhile, China's rural land system closely related to rural housing is the

\footnotetext{
${ }^{6}$ The State Council's government work report in 2014 emphasised the need to promote the new people-centered approach to urbanisation and proposed for the first time to focus on solving the 'three 100 million people' issue, that is, 'promoting the settlement of about 100 million agricultural transfer population in cities and towns, renovating the urban shanty towns and urban villages where about 100 million people live, and guiding the urbanisation of about 100 million people in the central and western regions.'
} 
main reason for the agricultural transfer population's short-term and highly mobile migration (Zhao 1999a, b; Yan et al. 2014).

The development and evolution of housing policies for rural migrants since 1998 can be divided into three periods: the lack-of-policy period from 1998 to 2004, the multi-party exploration period from 2005 to 2010 , and the unified integration period from 2011 to the present.

\subsubsection{The First Stage: Lack-of-Policy Period (1998-2004)}

During this period, the rate of internal migration slowed and labour shortages began to appear in the absence of sufficient rural migrants. In 1997, as the financial crisis in Southeast Asia broke, China's economic development slowed, and many township enterprises went bankrupt. In addition, in the middle and late 1990s, large numbers of employees in state-owned enterprises were laid off, urban employment intensified, and internal migration again increased, but at a slower rate.

As China's economic development gradually stabilised in the early 2000s, the rate of rural-urban migration increased. At the beginning of 2004, enterprises in Guangdong, Fujian, Zhejiang and other economically developed southeast coastal areas found it harder to recruit workers. In the second half of 2004, labour shortages spread across the country, although the pattern and intensity varied across different regions. Across inland provinces such as Jiangxi and Hunan, the traditional sources for migrant labour, enterprises found it harder to recruit workers. Authors such as Cai (2010) believe that 2004 was the 'Lewis Turning Point' when the growth rate in labour demand exceeded the growth rate of supply. There has been a nationwide labour shortage since 2004, and wages have increased significantly since that time. In 2004, the National Bureau of Statistics conducted a sample survey of 68,000 rural households and more than 7,100 administrative villages in 31 provinces (regions and cities). It estimated that the number of rural migrants who worked outside of their hometown in that year was about 118 million, accounting for $23.8 \%$ of the rural labour force. If the rural labour force employed in local township enterprises were to be included, the total number of rural migrants could be as high as around 200 million. ${ }^{7}$

There were no specific policies for rural migrants between 1998 and 2004, and there were only occasional references in some related policies. At this stage, the housing problems facing rural migrants steadily worsened. Specific policies for rural migrants were more concerned about employment restrictions, wage arrears and other aspects, with few directly relating to housing issues. In July 1998, the State Council issued the Notice on Further Deepening the Reform of Urban Housing System and Accelerating Housing Construction, clearly requiring all provinces, autonomous regions, and municipalities directly under the central government to stop the physical

\footnotetext{
${ }^{7}$ Research Group of the State Council Research Office: Investigation Report on Chinese Migrant Workers, China Yan Shi Press, 2006 Edition.
} 
distribution of housing in the second half of 1998 in order to phase in the monetisation of housing allocation. China's real estate market began to take shape from this point, and the urban housing market also entered a highly market-oriented stage. The housing situation for rural migrants changed as the proportion of rental houses increased while the proportion of accommodation provided by work units decreased. Migrants' expenditure on accommodation increased in relative terms, without any improvement in housing conditions. Levels of satisfaction with the available accommodation declined as accommodation problems for rural migrants mounted. In 2003, the General Office of the State Council acknowledged the need to improve living and working conditions for internal migrants. Policies at this time were mainly concerned with improving the basic health and safety conditions within rural migrants' housing.

At this stage, economic growth became an important theme within China's macroeconomic policies to lessen the impact of the Southeast Asian economic crisis. The stimulation of domestic demand was a key factor, and housing marketisation played an important role in this process. The ability of rural migrants to enter the housing market became one of the driving forces for economic growth.

\subsubsection{The Second Stage: Exploration Period (2005-2010)}

As the numbers of rural migrants increased across China's towns and cities, their living conditions attracted more attention from social services and sociologists. At the end of 2008, the National Bureau of Statistics established a statistical monitoring and investigation system for rural migrants. For the first time the recording of statistics relating to rural migrants was supported by authoritative data. In 2008, the total number of rural migrants nationwide ${ }^{8}$ reached 225 million. In 2010, the had risen to 242 million, an increase of 12.45 million over the previous year. The increase of $5.4 \%$, can be taken as the high-water mark for the growth in rural-urban migration. As China's macroeconomic development stabilised, the accumulated housing problems facing rural migrants became increasingly apparent. Central and regional levels of government have issued policies on rural migrants' housing since 2005.

At the national level, housing policies for rural migrants have shifted from ownership to user rights. From 2005 to 2007, the housing policies for rural migrants focused on the purchase of housing and housing provident funds for rural migrants. From 2005, research and the resolution of migrant housing problems was first incorporated into the work of the Ministry of Construction. From 2007, the Ministry of Construction proposed gradually expanding the legal coverage of the housing fund system to include rural migrants with stable occupations in cities for the first time.

\footnotetext{
${ }^{8}$ The statistical definition of migrant workers is the workers who still hold rural registered permanent residence and are engaged in non-agricultural industries locally or have been employed outside their hometown for 6 months or above. Unless otherwise noted, the data of migrant workers used in this study are all from the National Monitoring and Survey Report on Migrant Workers of the National Bureau of Statistics.
} 
From 2007 to 2010, housing policies for rural migrants shifted further from ownership to user rights. Measures included compliance with basic health and safety conditions, and the development of collective dormitories on industrial sites which were not to be sold as commercial housing. Renovation of urban villages would consider the living needs of rural migrants, and collective dormitories would comply with urban planning and overall land use standards where conditions permitted. Accommodation for rural migrants would be built under government guidance and operate according to preferential market policies for affordable housing. Rent would be maintained at a reasonable level for rural migrants.

It is worth noting that these measures differed from previous legislation. First, it was clearly proposed that dormitories constructed in development zones and industrial parks could only be rented to rural migrants, and not be sold as commercial houses. Second, it was stressed that, where conditions permit, housing that met the particular needs of rural migrants should be built and rented to them as a specific group. There is no mention of payment of housing provident funds to enable rural migrants to purchase or rent their own houses. These new measures represented a shift from ownership to rental rights against the background of increased worker mobility and a lower level of house purchase.

At the same time, more specific policies were introduced to address issues of responsibility and governance in addressing housing conditions, such as the provision of free or subsidised accommodation and low-cost leasing. When rural migrants make their own residential arrangements, employers should subsidise their rental payments. Those enterprises with large numbers of rural migrants should make full use of their own employee dormitories or raise housing resources for rural migrants by leasing and purchasing. Collective dormitories for rural migrants built in a centralised way should be left to rural migrants and not sold or rented as commercial housing. There could also be active measures on the urban-rural fringe to encourage local residents to rent their own housing to rural migrants.

Regional governments have also explored specific policies and practices to resolve migrant housing issues at a local level. Provinces and cities have issued a series of local supporting policies following the lead of the central government. The 'Chongqing Model' has emerged as a prominent measure, one which transforms vacant houses or unfinished buildings into rural migrants' apartments. The 'Changsha Model' is another initiative that provides rural migrants' apartments across rural collective land in the urban-rural fringe. The 'Shanghai Model' concentrates migrant accommodation in industrial parks while the 'Huzhou Model' establishes a housing provident fund system adapted to the needs of rural migrants.

The Chongqing Model: Chongqing was one of the earliest cities to explore and resolve the housing problem of rural migrants in China. The city authorities transformed vacant or unfinished buildings into rural migrants' apartments. Typical examples include the 'Bangbang Apartment' and 'Yangguang Apartment,' which transform vacant or unfinished buildings scattered across the city into low-cost apartments.

In Hunan Province, the Changsha Model was also among the earliest cities to adopt targeted measures to address the issue of migrant worker accommodation. 
The authorities built on rural collective land across the urban-rural fringe with the 'Jiangnan Apartment' as the representative example.

The Shanghai Model saw the centralised concentration of migrant apartments in industrial parks. Its typical representative is the 'Yongsheng Rural Migrant Workers' Apartment' in Malu Town, Jiading District, Shanghai.

The Huzhou Model incorporates rural migrants into the housing provident fund system and formulates a special funding policy suitable for their needs. Rural migrants have lower incomes than permanent residents and are highly mobile. To address these particular factors, Huzhou City introduced an innovative policy by establishing housing provident funds for rural migrants. It introduced a low threshold to encourage take-up and allowed those leaving employment to withdraw funds at any time and those withdraw funds for the housing rents. The model also provided preferential housing loans and interest subsidies for poorer families and supported rural housing construction.

At this stage, both central and local governments have introduced various migrant housing policies and actively sought to resolve housing issues. Measures include adjustments in policy focus, assignment of responsibility and programmes that meet particular local conditions.

\subsubsection{The Third Stage: Unified Integration Period (2011 to Present)}

The annual growth of migration within China declined from around 10 million between 2011 and 2012, to around six million between 2013 and 2014 and to around four million from 2015 to 2016. The total number of rural migrants reached 288 million by 2018, with less than 2 million being recent migrants. Since 2014, the total growth rate has remained below $2 \%$ (see Fig. 9.2). Housing policies have continued to respond to these developments with various improvements, increased integration and realignments. Under current conditions, policy changes relating to rural migrants' housing can be summarised as follows.

First, the responsibility for migrant housing has shifted from employers to local authorities. In September 2011, the General Office of the State Council proposed, to adhere to the principle of owner investment and to actively explore recovery of investment in publicly owned rented property. Local authorities would be empowered to fulfil their responsibilities within overall guidelines set by provincial people's governments. Municipal and county-level people's governments would be responsible for the specific implementation of policy, including preliminary work, construction funds, land supply, quality control, affordable housing rental management and supervision. This was a complete contrast with previous legislation, which put the onus on employers and placed responsibility at the government level.

Second, rural migrants were to be included in the urban housing security system. The General Office of the State Council proposed to provide publicly owned rented 


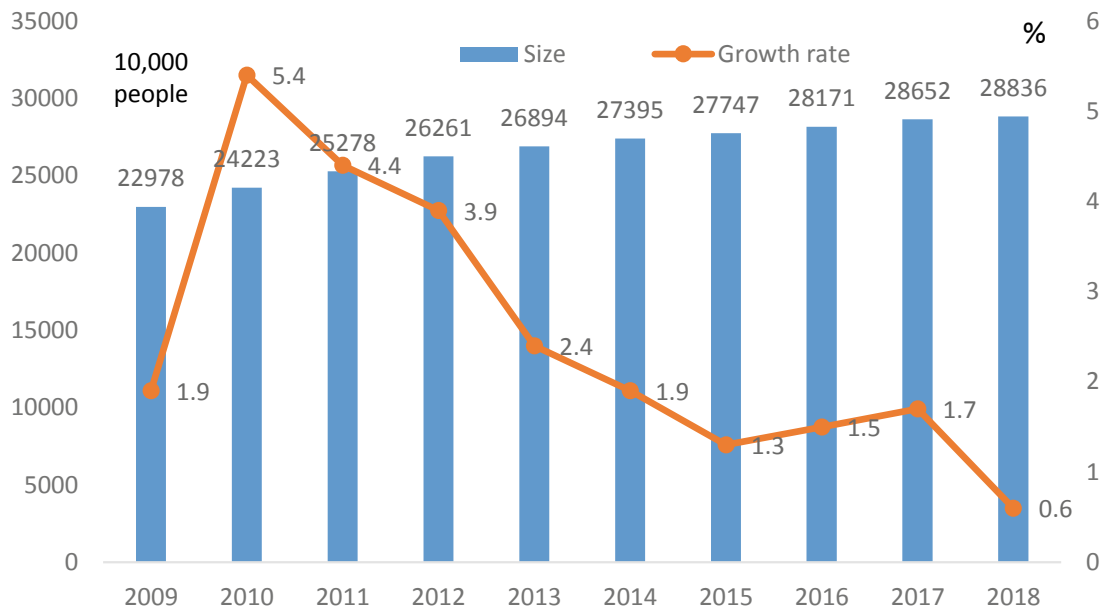

Fig. 9.2 The size and growth rate of migrant workers in China. Data source National Monitoring and Survey Report on Rural Migrant Workers of the National Bureau of Statistics over the years

accommodation to poorer or middle-income families and to recent migrants as well as those with stable occupations. The new provisions differ notably from previous legislation in that the caveat, 'where conditions permit' was removed and the scope extended to include recent migrants as well as those who had long become established in China's cities. In a further development, Opinions of the State Council proposed to include both 'qualified' rural migrants and those in stable employment into housing security and funding systems, and to include rural migrants alongside the locally registered population within the scope of housing security rights.

Third, various measures have been implemented to improve housing rights and security. Construction of publicly owned rental housing or collective dormitories was encouraged in various announcements focused on the provision of public rented accommodation for rural migrants with stable occupations. At the same time, industrial zones were to provide a mix of rented accommodation and dormitories in accordance with the principle of intensive land use. The State Council also provided guidance on the provision of residential accommodation alongside office and production space in industrial parks.

In addition, policies have been introduced to help migrants with housing purchases. The State Council proposed to actively support eligible rural migrants to purchase or rent commercial housing, and enjoy preferential deed tax and stamp tax. It advocated the gradual inclusion of migrants with stable occupations within the scope of housing provident funding. The State Council also proposed adjusting and improving the differentiated housing credit policy, developing the individual housing loan insurance business, improving the housing financial service level for middleand low-income groups such as rural migrants, and encouraging and guiding farmers to purchase houses near small and medium-sized cities. 
Moreover, the State Council proposed to accelerate the promotion of rental subsidy systems, and use market and government subsidies to support eligible migrants to rent accommodation through the housing rental market, and to strengthen the environmental renovation and comprehensive management services of urban villages and shantytowns, so as to improve the living conditions of rural migrants.

\subsection{Evaluation of Housing Policies}

In order to evaluate the effectiveness of these policies, we must first establish the assessment criteria. Various criteria have been put forward by academic institutions, which can be summarised as follows:

- Fairness of policy objectives,

- Synchronisation with legal and other policies,

- Appropriateness of policy,

- Enforceability of policy,

- Actual effect of policy.

We will now use these criteria to evaluate housing policies for rural migrants in China.

\subsubsection{The Fairness of Policy Objectives}

Housing policies for Chinese rural migrants started from scratch and represented a milestone in the development of social equity. The intensive introduction of housing policies for rural migrants after 2005 shows that the government has paid more attention to improving the living conditions and social security of rural migrants. However, policy objectives remain very general rather than specific, typified by phrases such as 'improving the living conditions of rural migrant workers' (JZF [2007] No. 276), 'significantly improving the living conditions of rural migrant workers' (GBF [2011] No. 45), etc. More detail on specific measures of implementation is needed.

Housing policy for rural migrants still lacks a wider conceptual framework that integrates urban and rural planning. Under the planned economy system, the 'welfareoriented public housing' of urban residents and the 'homestead' of rural residents were both a specific form of housing security system and guaranteed 'shelter for all' under low productivity levels (Chen 2006). During the process of urban housing system reform, 'welfare-oriented public housing' for urban residents became private property, while the 'rural house site' is still a potential asset under the collective ownership of rural land that cannot be effectively realised. The relationship between the housing security of rural migrants in cities or towns and the 'rural house site' 
cannot be ignored. It explains why the rural house site in some areas can exchange as urban real estate. This shows that the objectives of existing housing policies for rural migrants in China lack an overarching planning framework spanning urban and rural areas.

\subsubsection{Synchronisation with Legal and Other Policies}

There is currently no basic legal guarantee for the existing housing policies for rural migrants, and there are contradictions between the solutions put forward to resolve migrant accommodation issues current land policies. The formulation of a more comprehensive legal system is key to resolving housing problems. Most of China's housing policies are in the form of 'Guidance Opinions' and 'Notices' from government departments at various levels and have not been consolidated in law. Old practices from the Maoist era, such as 'one case one meeting' and 'handle special cases with special methods', still persist, and some policies even have obvious conflicts with current land policies (Lv et al. 2007).

The practice of using rural collective land to build rural migrant workers' apartments contradicts the Land Administration Law of the People's Republic of China. Article 63 of Land Administration Law (2004 Revision) which clearly stipulates that 'The right to use land collectively owned by farmers shall not be sold, transferred or leased for non-agricultural construction.' Apartments for rural migrant workers clearly belong to the category of non-agricultural construction. The conversion of redundant factories, libraries and other public facilities into migrant accommodation and the transfer of land in industrial parks for migrant apartments are likely to change the use of state-owned land. Suppose land was originally designated for industrial and mining use rather than residential purposes. In that case, the construction of rural migrant workers' housing on this land violates the provisions of Land Administration Law. Current legislation ensures that development can only take place on state-owned land in accordance with the rights and conditions that originally applied. The use of redundant factory buildings or land released from bankrupt or closed enterprises for migrant accommodation may conflict with the local government's land acquisition and reservation policies.

\subsubsection{The Appropriateness of Policy}

The appropriateness of housing policies for rural migrants in China can be evaluated from the perspectives of housing security coverage, security methods and standards. Rural migrants are included within China's urban housing security system, and housing security has also been diversified. Although there have been great strides in China's housing policies for rural migrants, housing security standards have yet to be improved. 
There are substantial regional differences in rental and spatial policies. The prevailing guidance on rent for publicly owned rental housing is that it should be, 'reasonably determined according to the principle of slightly lower than the market rent' (GBF [2011] No. 45). The spatial standard for public rental housing first requires that the single floor area shall be strictly controlled below 60 square metres (JB[2010] No. 87), and then stipulates that small apartments with a single floor area of about 40 square metres should be the dominant form (GBF [2011] No. 45). Can superlow rents be sustainable? Will rural migrants actually be able to rent houses at rates slightly below the market standard? And are the standards for suitable dormitory areas incompatible with the trend for family members of rural migrants to move with them to the city? These questions all need to be answered.

\subsubsection{The Enforceability of Policy}

Capital investment issues mainly arise during the implementation of existing housing policies for rural migrants, when responsibilities are divided between central and local governments. The GBF [2011] No. 45 Document proposed that provincial government should take overall responsibility for affordable housing projects in their region. Municipal and county people's governments would be responsible for implementing specific preliminary work, construction funds, land supply, quality control, rental and sales management and supervision of affordable housing. The central government would continue to increase funding subsidies while local government should prioritise affordable housing projects in their budgetary arrangements and increase financial investment. It can be seen that local governments are mainly responsible for raising funds for affordable housing, and the local government's financial expenditure is often under great pressure. From 2009 to 2018, the national fiscal expenditure for housing security increased from RMB 180.34 billion to RMB 680.637 billion, an average annual increase of $30.82 \%$. Local government fiscal expenditure has stood higher than $90 \%$ since 2011, and central government expenditure remains below $10 \%$.

However, for local governments with a long-standing gap between revenue and expenditure, housing security exerts a double pressure, incurring both a decrease in revenue and an increase in expenditure. Local governments can consequently be passive about providing housing security, but they have positive power to increase income by selling land, stimulating economic growth through real estate and maintaining high house prices. In the new round of local government housing construction plans over recent years, the scope of government housing security is often smaller than that determined by the central government (Dong 2011). This shows that there is a difference between the central and local governments in demand for housing security. In this context, it is more difficult to implement housing policies for rural migrants. 


\subsubsection{The Actual Effect of Policy}

Work is still in progress in devising policy solutions for migrant housing problems, and the practical effect is limited. In 2018, less than $3 \%$ of urban-rural migrants purchased affordable housing or rented publicly owned accommodation. The proportion of rural migrants who enjoy urban housing security is still very low. At the same time, there are continuing housing issues facing locally registered residents, which remain a priority for local governments. Local policies that aim to address migrant accommodation problems leave issues relating to the local urban registered population unresolved. As a result, the practical role of these policies to resolve migrant housing problems remains limited.

\subsection{Policy Implications}

Improving housing regulations and policies is essential to the process of 'new urbanisation' and the urbanisation goal of 'three 100 million people'. As well as steering population migration by employment, it is also necessary to improve housing regulations and policies to reduce obstacles to migration. We now explore these policy implications in more detail.

\subsubsection{Coordination of Urban-Rural Land and Housing Systems}

The trend for rural-urban migration is likely to continue for some time. In the long run, land and housing system reforms are necessary for the overall planning of urban and rural development. To formulate housing policies for rural migrants, it is necessary to first establish the long-term goal and concept of overall urban and rural planning. There is a major contradiction between the dual housing consumption of rural migrants in urban and rural areas. While rural migrants living in the city 'consume' housing there, they also typically have a home in rural areas. This has led to a disconnect between migrant housing patterns across urban and rural areas, which leads to the phenomenon described as, 'no one lives in rural housing and people have no houses in the cities where they work.' Rural migrants live in the city most of the time, and their income mainly flows into those cities rather than back to their rural homelands. On the other hand, there are many rural migrants who plan to build or purchase houses in their hometown, while few intend to purchase houses in the city. Given the housing difficulties facing rural migrants flowing into urban areas and redundant rural homesteads and houses, the establishment of an overall, integrated 
urban-rural land and housing system should be a long-term policy goal. The key is to promote systematic rural land reform, speeding up the establishment of a free market for homesteads and rural houses. That way the families of rural migrants who plan to settle in urban areas can have channels to realise their rural assets so as to increase their ability to afford housing stock in towns and cities. Once they have realised their rural assets, such families could obtain urban housing through market transactions. Those currently unable to afford urban housing could then enjoy the same housing security as other urban residents. Even if rural migrants' families are not willing to realise these rural assets, as long as the free trade market for rural land is established, the value of such assets can be evaluated against the market transaction price and included into their total household assets. If they meet the access qualifications for an overall urban-rural housing security system, they can also enjoy the same housing security as other urban residents. By setting integrated planning for urban and rural land and housing systems as a long-term goal it will become possible to improve policy development and delivery.

\subsubsection{Housing Laws, Regulations and Security Systems}

Market and government are the two channels that allocate housing resources. Affordable housing provides the dividing line between market allocation and housing security. Those able to purchase or rent houses can do so through the open market, while families with insufficient collateral require housing security provided by the government. The majority of migrant families have insufficient resources to afford to buy houses in the city and must rely on government intervention. The urban housing market erects barriers to resolving housing problems. It is both unrealistic and impossible to solve migrant housing problems without considering the issues facing other urban low-income groups. China's rural migrants make up a significant proportion of such groups, but they are by no means alone. Any solution to migrant housing issues should be carried out under a wider framework of tackling urban inequality as a whole. Equally, the level of housing security for rural migrants depends on the overall context across the city as a whole. China's urban housing security systems still have many problems and lack sound legal guarantees. From international experience, the establishment of a comprehensive legal system is an important factor in resolving housing problems. For example, Japan's Public Housing Law, Residential Corporation Act, Basic Residential Law, etc. clearly defined the housing construction objectives, capital sources and other policy safeguards in a legal form. In China, specific measures to resolve migrant housing problems may not integrate or even conflict with legal and other policies. The development and revision of appropriate regulations are required to improve China's housing security system to benefit rural migrants. This will take a long time, so it is appropriate to design policies as a long-term strategy for improving these systems. 


\subsubsection{Affordable Housing}

Poor housing conditions and the inability to afford urban property militate against the integration and settling of rural-urban populations. The key to solve housing problems is not the right to own property so much as the ability to obtain safe, healthy and stable housing. Issues of both supply and demand require attention. Supplyside measures may mainly include: combining the reconstruction of shantytowns (Chap. 7) and urban villages (Chap. 6) with the elimination of inferior housing that falls below health and safety requirements. Alongside these measures should be the provision of affordable homes for rural migrants and their families. Ways to extend housing property rights to rural migrants could be explored both for rented and purchased accommodation. Low-cost housing purchase opportunities could run alongside the encouragement to vacate vacant housing land in rural areas. On the demand side, measures could focus on improving access to affordable housing, and expanding the proportion of monetary subsidies to remove barriers and ensure the reasonable flow of population.

There are clear regional differences in the ability of migrants to afford property, so it is necessary to formulate regional housing policies. Government contributions to housing security should be greater in eastern provinces than in central and western regions, with the focus on improving the ability of migrants to obtain property rights. In the central region, the market can chiefly meet the housing needs of rural migrants. Housing security should improve the ability to rent or purchase houses by combining low-cost purchase opportunities with encouragement to vacate vacant rural housing land. The western region could adopt policies similar to those in the central region, but with stronger government intervention, and more emphasis on the improvement of housing conditions.

\subsubsection{Land Reform}

Land system reforms are closely connected with the reform of the household registration system. The main barrier to permanent urban settlement for rural migrants derives from land issues in their rural homelands, especially those around the rural homestead'. 9 There is currently an urgent demand for rural land system reform. Failure to address this has slowed the urbanisation process. The focus for rural land system reform lies in the reform of the rural house site system. Land reform is necessary to facilitate rural-urban migration. The land rights and interests of rural migrants mainly comprise contractual land management rights and rights to homestead use. The first is the right to own agricultural land, and the second is the right to own sites set aside for house building as collective construction land.

\footnotetext{
${ }^{9}$ The rural house site is the land occupied by the peasant family as the residential base, and its ownership belongs to the members of the rural peasant collective.
} 
There are three key points in the reform of contractual land management rights. One is to stabilise the contractual relationship and clarify specific long-term provisions. The second is to grant household certificates and to grant collective property rights to individual members of collective economic organisations. The third is to promote the orderly transfer and mortgage of land management rights and realise their potential value.

The reform of homestead rights can be promoted from three aspects. The first would be to establish an integrated urban and rural construction land market. Under the present land system framework, urban land is owned by the state- the state occupies land on behalf of all the people. Rural land, however, is collectively owned. Both systems are concrete manifestations of socialist public ownership. China's urbanrural division within the construction land market cannot be sustained indefinitely. The establishment of an integrated market for construction land across rural and urban areas can only be achieved by transferring collective rural construction land into stateownership. The specific means to achieve this needs to be considered thoroughly and comprehensively. The second measure would be to explore feasible routes for urban residents to purchase homesteads and commercial houses. Taxation and other fiscal systems could be designed to enable urban residents to purchase homesteads and market-value houses, enabling rural populations to realise their assets and improve the utilisation and efficiency of rural land and houses. The third would be to improve mechanisms and management for balancing land index differentials between urban and rural development sites. To establish an integrated urban and rural land market, we need to take account of fluctuating land use quotas set by the government, which determine the amount of land that can be used for conversion and development, the construction of new villages, and the refurbishment of new villages dilapidated rural housing. These quotas need to be better coordinated between rural and urban areas. Proceeds from construction land index trading could then be used for land consolidation and reclamation in order to transfer subsidies to migrant populations. The increase in urban construction land could then link with the number of rural migrants coming into the city.

\subsubsection{Urban Housing Management}

The rental market appeared relatively late in Chinese cities. As urbanisation gathered momentum an influx of foreign nationals created rapid development in the rental market. In sharp contrast, the government's management of the housing rental market is yet to be implemented. The result is an often chaotic rental market. China should formulate the industry standard for managing rented housing. It should institutionalise control of this market from the perspective of market access, only allowing the provision of accommodation that provides appropriate living standards for rural migrants. Specialised departments are needed to supervise the management of the housing rental industry. At the same time, the government could introduce a series of policies to benefit the people, such as providing low-cost rental housing for rural 
migrants via government channels, and building an open and transparent rental information circulation system, etc., to allow rural migrants easier access to information on appropriate rental options.

There is also a need to strengthen the management of temporary housing. Many rural migrants are engaged in construction, logistics and other relatively low-end manual labour-intensive industries. In order to save housing costs, they usually live in temporary sheds or densely populated dormitories provided by employers. Adequate living standards within such temporary housing are not always guaranteed. The government could therefore regulate living conditions to ensure they are maintained to a safe and adequate standard. In addition, the government could encourage employers to build employee dormitories to provide safe and comfortable housing for rural migrants through land concessions, tax relief and other measures.

Overall, the goal should be to bring rural migrants fully within the scope of urban housing security. This has been a major Chinese aspiration for more than a decade. It is, however, difficult to achieve this goal under current conditions, and therefore, a number of changes are needed. Rural migrants need to be guaranteed access to the housing provident fund. ${ }^{10}$ Where rural migrants hold stable occupations in cities, the government could allow them to use grants or loans to pay their rent and improve their living conditions. A low-rent housing system for rural migrants would then be gradually improved. Current low-rent or affordable housing provision mostly caters for low-income urban groups. To resolve urban housing problems facing rural migrants, the workers themselves would be among the beneficiaries of low-rent housing systems. Only when rural migrants have their own houses in the city, can the permanent transfer of rural population and the urbanisation of China be fully realised.

\subsection{Conclusion}

The mass migration of rural workers to the cities has posed major challenges for the housing system in China. Ambitious policy goals have been proposed, but they have been vague and disjointed, and as a result, they have failed to impact the living standards of rural migrants significantly. In order for China to achieve its vision of 'new urbanisation', there needs to be a coordinated approach to housing policy that is grounded in a broader strategic approach to urban planning. Fundamental housing and land reforms are needed to bring about system-wide coherence and lasting change. An essential complement to such reforms is a more comprehensive and coherent housing safety net to protect the most vulnerable rural migrants. The private renting and homeownership sectors also need to be reformed in the light of best practices observed in countries with more established housing market institutions and regulations.

\footnotetext{
${ }^{10}$ The housing provident fund is a form of long-term housing savings that both employers and employers pay into, with equal contributions form each.
} 


\section{References}

Berger MC, Blomquist GC (1992) Mobility and destination in migration decisions: the roles of earnings, quality of life, and housing prices. J Hous Econ 2(1):37-59

Brueckner JK, Lall SV (2015) Cities in developing countries: fueled by rural-urban migration, lacking in tenure security, and short of affordable housing; Duranton G, Henderson JV, Strange WC Handbook of regional and urban economics, vol 5. Elsevier, pp 1399-1455

Cai F (2001) Two processes and institutional barriers in migration. Sociol Stud 04:44-51

Cai F (2010) Demographic transition, demographic dividend, and lewis turning point in China. Econ Res J 04:4-13

Cai H, Wang Jin (2007) A study on rural migrant workers' permanent migration intentions. Sociol Stud 2007(06):86-113

Chen H (2006) Develop housing security system to alleviate the conflicts of housing supply and demand. Res Econ Manag 03:9-12

Dong X (2011) A study of changes and present situations of the housing security coverage of Chinese government. Contemp Financ Econ 05:84-91

Dong X (2012) Dynamic trends and structural differences: a comprehensive measurement of housing affordability of China's housing market. Econ Manag 2012(06):119-127

Dong X (2015) Housing affordability and permanent migration willingness of agricultural transfer population. Chin J Popul Sci 2015(06):91-99

Li B (2008) Structured urban housing: a mechanism of selection for migrants. Chin J Popul Sci 04:53-60

Lv P, Zhou T, Gao R (2007) The conflict between rural migrant workers' housing solution and current land policy. China Real Estate 03:49-51

Ma J, Meng F (2003) Analysis on influence factor that farmers transplant can't be lasting-positive analysis according to Shengzheng City. Reform 04:77-86

Ren Y, An S (2011) Labor migration, urbanization and labor shortage. economics. Information 05:64-68

Yan X, Bauer S, Huo X (2014) Farm size, land reallocation, and labour migration in rural China. Popul Space Place 20(4):303-315

Zhao Y (1999a) Leaving the countryside: rural-to-urban migration decisions in China. Am. Econ. Rev. 89(2):281-286

Zhao Y (1999b) Labor migration and earnings differences: the case of rural China. Econ Dev Cult Change 47(4):767-782

Open Access This chapter is licensed under the terms of the Creative Commons Attribution 4.0 International License (http://creativecommons.org/licenses/by/4.0/), which permits use, sharing, adaptation, distribution and reproduction in any medium or format, as long as you give appropriate credit to the original author(s) and the source, provide a link to the Creative Commons license and indicate if changes were made.

The images or other third party material in this chapter are included in the chapter's Creative Commons license, unless indicated otherwise in a credit line to the material. If material is not included in the chapter's Creative Commons license and your intended use is not permitted by statutory regulation or exceeds the permitted use, you will need to obtain permission directly from the copyright holder.

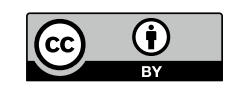

